\title{
Explicating mechanical and electrical knowledge for design phase of green building projects
}

\begin{abstract}
Construction projects usually encompass numerous disciplines, requiring the integration of knowledge from civil, mechanical, electrical and other engineering domains. Some researchers contend that the integration of construction knowledge and experience at the early design phase would improve the overall project performance. Domination of tacit knowledge during design phase of building projects is the major source of knowledge flow problems between involved professionals. Therefore, this study intends to explicate the required mechanical and electrical knowledge which has to be considered during the conceptual design phase of a green building project. To fulfil this goal, a case study has been conducted to specify the entity of the required mechanical and electrical knowledge. The primary method for the data collection here is observation. Furthermore, this study employs the triangulation method in order to validate the collected data. The results contain the required mechanical and electrical knowledge which has to be considered during the conceptual design phase of a green building project.
\end{abstract}

Keyword: Green building; Knowledge flow; Sustainable design informatics; Tacit knowledge 